\title{
Ground temperature gradients surrounding horizontal heat pump collectors in a maritime climate region
}

\author{
M. Greene, N. Burke, J. Lohan \& R. Clarke \\ Department of Mechanical and Industrial Engineering, \\ Galway-Mayo Institute of Technology, Galway, Ireland
}

\begin{abstract}
While earlier investigators have undertaken to identify ground temperature gradients about horizontal heat exchangers or collectors in continental climates, this paper reports the findings of a similar study undertaken in the Irish maritime climate. The ground source heat pump employed extracts heat from the ground using a horizontal collector buried at a depth of $1 \mathrm{~m}$. Measurement of both the local air and ground temperature was made during the 2007 Winter-Spring heating season. Ground temperature gradients were established to a depth of $1.8 \mathrm{~m}$ by measuring temperature at up to seven different vertical depths. Temperature gradients are presented for five different locations that include one reference location outside the collector region and four locations within the collector region. These highlight the impact of diurnal and seasonal factors, as well as ground cover and composition and heat pump operation on ground temperature. These results will support the development of optimised collector design and collector ground composition for maritime climates, as well as providing important input data for the validation of numerical models.
\end{abstract}

Keywords: ground/soil temperature gradient, ground source heat pump, horizontal collector, maritime climate, thermal storage, renewable energy.

\section{Introduction}

Increased awareness of climate change and the need for sustainable development is creating renewed interest in natural resources and their utilisation [1,2]. This study focuses on characterising the latent thermal energy in the ground surface layer so that the design of Ground Source Heat Pump (GSHP) horizontal 
collectors might be optimised to maximise heat pump efficiency in maritime climate regions. The characterisation involved measuring vertical temperature gradients both inside and outside the collector region of a $15 \mathrm{~kW}$ GSHP, operating in the maritime climate of Galway, Ireland. While numerous research studies have informed horizontal collector design in continental climate regions, detailed experimental studies of this kind have not been reported for maritime climates. This paper seeks to address this deficit in the literature.

Influential studies that have informed collector design in continental climates involve experimental and numerical approaches and they include; Popiel et al. (Poland) [3]; Mihalakakou et al. (Ireland/Greece) [4, 5]; Inalli and Esen (Turkey) [6]; Chacko and Renuka (India) [7]; Bi et al. (China) [8]; Piechowski (Australia) [9]; Beltrami (Canada) [10]; and Algren (Minn., USA) [11].

Popiel et al. [3] reported measured vertical temperature distributions to a depth of $7 \mathrm{~m}$ for two ground cover types, a bare sandy soil car park and a grass covered lawn. The results highlighted short-term temperature fluctuations to $1 \mathrm{~m}$ and seasonal temperature fluctuations to as much as $7 \mathrm{~m}$. Hence collectors are buried to depths of $1.5 \mathrm{~m}$ to $2 \mathrm{~m}$ in continental regions. Sensitivity to the ground cover type was also reported with soil temperature beneath the car park $4^{\circ} \mathrm{C}$ higher on average than that beneath the lawn over the summer period, but this diminished to almost zero during winter. Sensitivity of soil temperature to ground cover type was also reported by Mihalakakou et al. [4, 5]. Both Timlin et al [12] and Pierson and Wright [13] highlighted the role that vegetation and its roots can play in altering the temperature and moisture distribution in the soil surface layer. These studies highlight the impact of climate, surface cover and depth have on ground temperature gradients. These are examined in this paper.

Inalli and Essen [6] presented experimental results for a $3.5 \mathrm{~kW}$ GSHP which showed that the average Coefficient of Performance (COP) varied between 2.66 and 2.81 when the collector depth was increased from $1 \mathrm{~m}$ to $2 \mathrm{~m}$. This was attributed to a ground temperature variation between $9.2^{\circ} \mathrm{C}$ at $1 \mathrm{~m}$ and $13.9^{\circ} \mathrm{C}$ at $2 \mathrm{~m}$. This highlights that heat pump performance is influenced by collector depth and surrounding ground temperature and that the warmer soils are located at depths of $2 \mathrm{~m}$ during winter in continental climate regions.

While many of the cited studies are experimentally based, the literature is dominated by predicted results and Bi et al. [8], Piechowski [9], Beltrami [10], and Mei [14] are good examples of this approach. Campbell and Norman [15] present the basic models used for estimating a soils diurnal and annual temperature fluctuations at any depth, while Thomas and $\mathrm{Li}$ [16] modelled heat and mass transfer in soil using the de Vries method [17].

This paper presents vertical temperature profiles that highlight the impact of diurnal, climate and seasonal effects on soil temperature gradients inside and outside a heat pump collector region. A novel aspect of this study enables the influence of ground composition in the collector region to be assessed by comparing temperature gradients measured at four locations where the surface layer comprises different combinations of vegetation, ground cover type and ground material. Finally the impact of heat pump operation is also assessed. 


\section{Experimental facility and procedure}

An outline of the experimental facility and test procedure is presented in this section. Greater detail on the facility is also available from Lohan et al. [18]. Figure 1 identifies the $500 \mathrm{~m}^{2}$ collector region that lies beneath four typical but different ground cover types; grass, shrubbery, brick and porous brick. Ground temperature gradients or Profiles are recorded at locations identified by a 'P\#'. Note that both P1 and P2 lie outside the collector region and these act as reference sites for monitoring the ground response without the impact of the GSHP operation. Meanwhile P3 through P7 allow the combined effects of heat pump operation and ground composition within the collector region to be assessed.

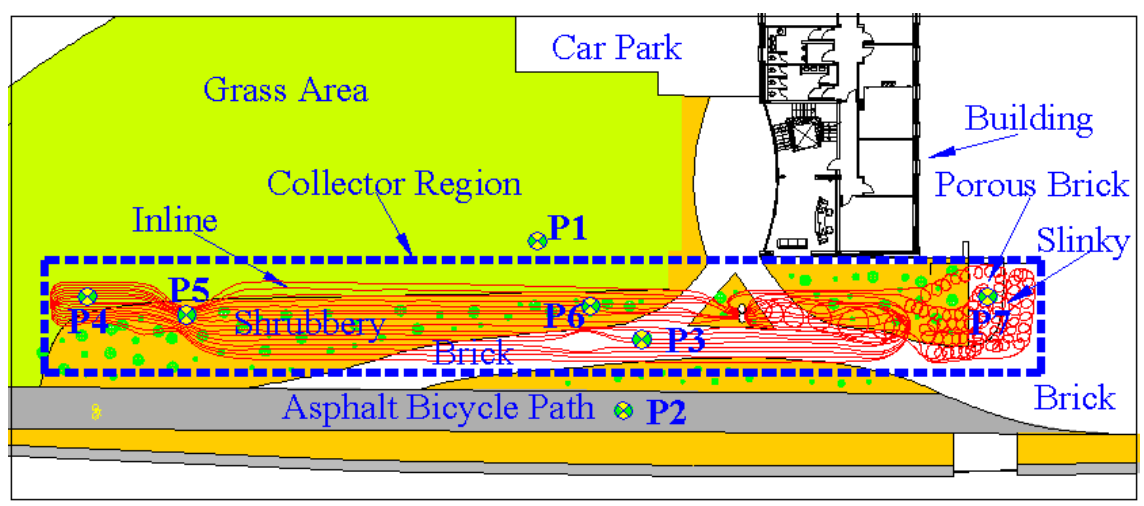

Figure 1: Plan view of the collector region showing its position relative to the building, ground cover types above collector and profile locations.

\subsection{Temperature gradients}

A cross sectional view of the five temperature gradients recorded in this study is presented in Figure 2. Each view shows the location of both the temperature sensors and the collector depth as well as ground composition, specifying the type of vegetation; cover and ground material. Note that P1 acts as a reference profile located in a grass-covered area outside the collector area. Results from P1 can be compared directly with P4 located in a grass-covered area within the collector region. Meanwhile the impact of shrubbery, porous and non-porous brick can be assessed using P5, P3 and P7 respectively. Also note the different proportions of topsoil, soil, sand and gravel that make up the ground composition within the collector area.

Ground temperature is monitored using 4-wire, PT100 Class A temperature sensors with a nominal accuracy of $\pm 0.1^{\circ} \mathrm{C}$ between $-5^{\circ} \mathrm{C}$ and $+5^{\circ} \mathrm{C}$ and $\pm 0.3^{\circ} \mathrm{C}$ between $+5^{\circ} \mathrm{C}$ and $+25^{\circ} \mathrm{C}$. Measurement accuracy was assessed using a D55SE Jofra calibrator and the calibration method reflects best practice outlined by Stum and accounts for transducer, wire and acquisition error [19]. The dry-bulb air temperature sensor has a calibrated accuracy of $\pm 0.35^{\circ} \mathrm{C}$ at $0^{\circ} \mathrm{C}$. 


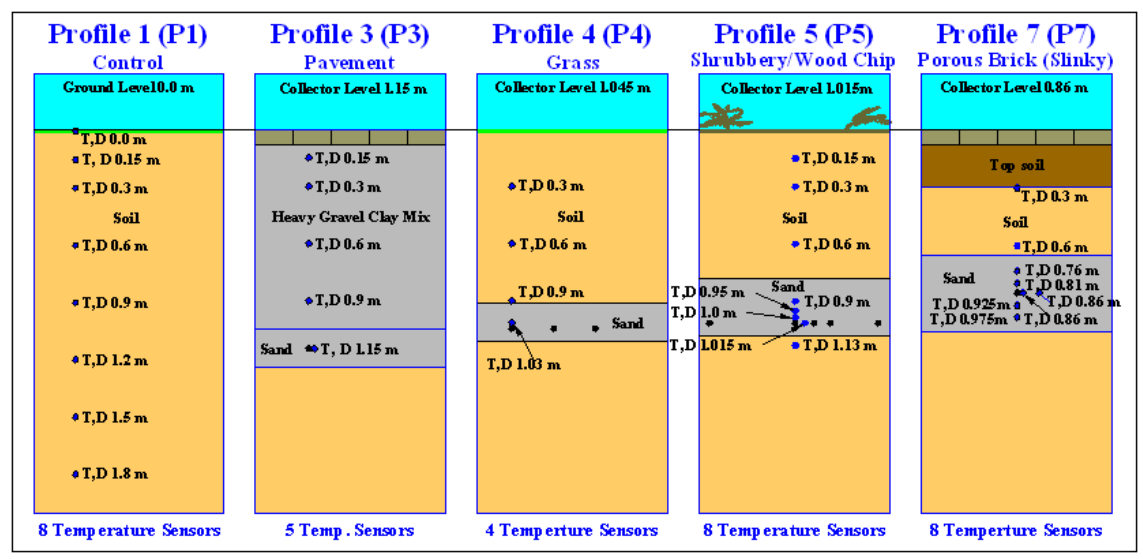

Figure 2: Cross sectional views of five vertical ground temperature profiles.

\subsection{Test procedure}

The $15 \mathrm{~kW}$ heat pump operates to meet the demand of the adjacent building and its performance was continuously monitored at 5-minute intervals along with climate and ground temperature from January through April, 2007. However, the data presented in this paper is confined to two, one-week long periods that are representative of the coldest (winter) and warmest (spring) air temperatures during this period, Table 1.

Table 1: Summary of climate data for the selected Winter and Spring periods.

\begin{tabular}{|c|c|c|c|c|c|}
\hline Period & Date & Tair (avg) & Tair (max) & Tair (min) & Sun (Hrs) \\
\hline Winter & $05 / 02-11 / 02$ & $+3.8^{\circ} \mathrm{C}$ & $+9.6^{\circ} \mathrm{C}$ & $-2.8^{\circ} \mathrm{C}$ & 16.4 \\
\hline Spring & $27 / 03-02 / 04$ & $+8.0^{\circ} \mathrm{C}$ & $+16.2^{\circ} \mathrm{C}$ & $+2.2^{\circ} \mathrm{C}$ & 61.1 \\
\hline
\end{tabular}

During the representative seven-day long 'Winter period' there was a total of 16.4 sunshine hours and an average air temperature of $+3.8^{\circ} \mathrm{C}$, with a maximum and a minimum temperature of $+9.6^{\circ} \mathrm{C}$ and $-2.8^{\circ} \mathrm{C}$ respectively. Throughout the representative seven-day long 'Spring period' there was 61.1 hours sunshine and an average air temperature of $+8.0^{\circ} \mathrm{C}$ with a maximum and a minimum temperature of $+16.2^{\circ} \mathrm{C}$ of $+2.2^{\circ} \mathrm{C}$ respectively.

For the winter period the heat pump and horizontal collector were operational for an average of 12 hours per day with an average heat extraction rate of $12 \mathrm{~kW}$. In the two weeks leading up to the Spring period the heat pump was turned off to allow ground temperatures within the collector region to recover to normal temperature. The horizontal heat pump was turned on at 00:00 on the 31/03/07 and was then operational for an average of 16 hours per day with an average extraction rate of $12 \mathrm{~kW}$. 


\section{Results}

Experimental results are presented in two formats; a) time-varying temperature plots for each temperature sensor in a given profile over the course of each test week and b) comparison of temperature gradients of each profile at one instant.

\subsection{Time varying temperature at the reference profile (P1)}

Time varying plots help one identify the diurnal air temperature fluctuations during the test week, how the amplitude of these fluctuations attenuate with depth and how the phase lag increases with depth. Figures 3 and 4 present these results for the Control profile P1 (Figure 1). As a result this data is independent of heat pump operation and solely reflects climatic conditions. Figure 3 presents the measured data during the selected 'Winter period' (Table 1) and these results can be contrasted against those for the warmer 'spring period' in Figure 4. Both Figures show ground temperatures at six measurement locations from the surface to the maximum depth of $1.8 \mathrm{~m}$ as well as the air temperature and the total daily sunshine hours. The sunshine hours were recorded off-site at Met-Eireann's metrological office located 60 miles south of Galway at Shannon airport.

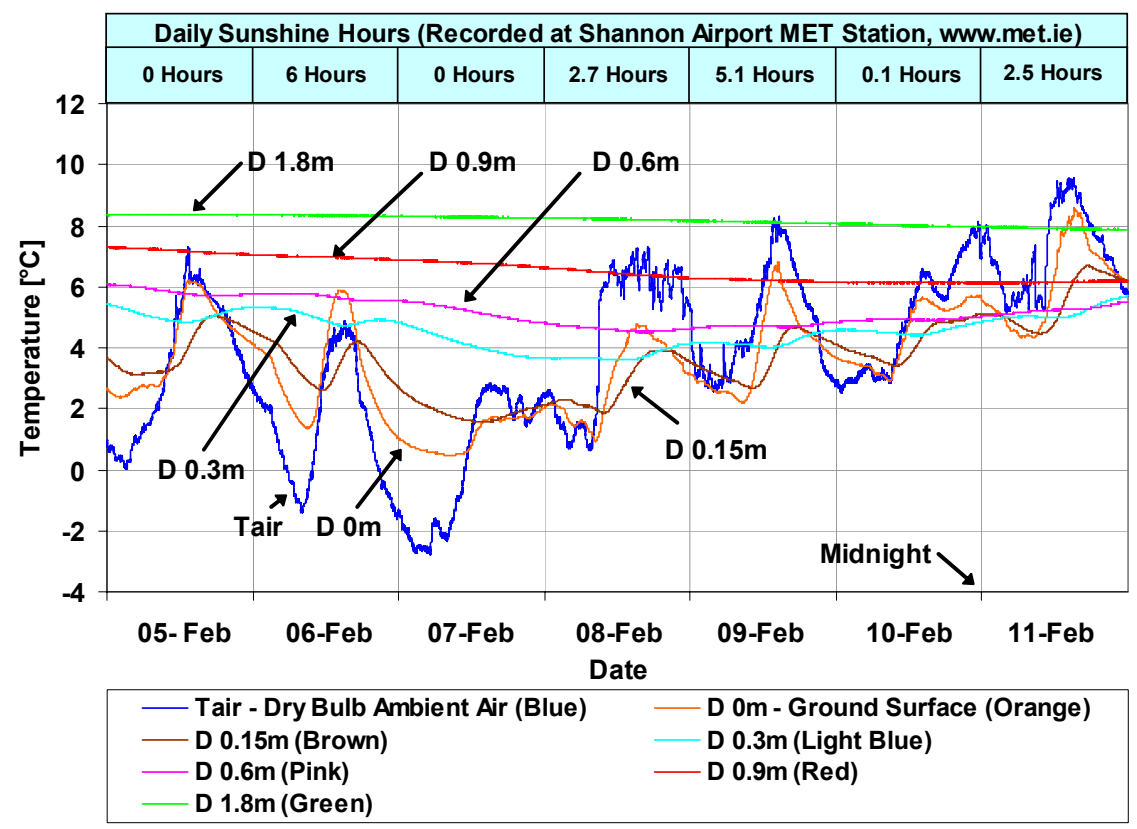

Figure 3: Fluctuations of air temperature and ground temperature with depth at the reference P1 location during the representative 'winter period'. 
At the soil-atmosphere interface it can be seen that during periods of low sunshine the ambient air temperature and sensible heat transfer dominate the surface energy balance. This is common to both maritime and continental regions.

However due to the combined effects of the Gulf Stream and Ireland's maritime climate, winter ambient air temperatures are significantly higher than those normally experienced in continental regions of the same latitude and as a result ground temperatures remain higher in maritime regions [20]. This allows horizontal collectors to be installed at approximately half the depth, at $1 \mathrm{~m}$ in maritime regions. Note from Figures 3 and 4 that diurnal fluctuations are attenuated to near zero below $0.6 \mathrm{~m}$ and the maximum temperature fluctuation between the Winter and Spring periods at the collector depth of $0.9 \mathrm{~m}$ was approximately $2.5^{\circ} \mathrm{C}$, ranging from a low of $6^{\circ} \mathrm{C}$ in Winter to a high of $8.5^{\circ} \mathrm{C}$ in Spring.

While Figure 3 depicts a particularly cold period during an Irish winter Figure 4 illustrates an unusually sunny period during the mild Irish spring. The effects of radiant heating of the ground surface layer is evident at D $0 \mathrm{~m}$ where long periods of sunshine result in ground surface temperatures that exceed air temperature. These results contrast with those presented in Figure 3 where the air temperature dominated the ground surface temperature fluctuations.

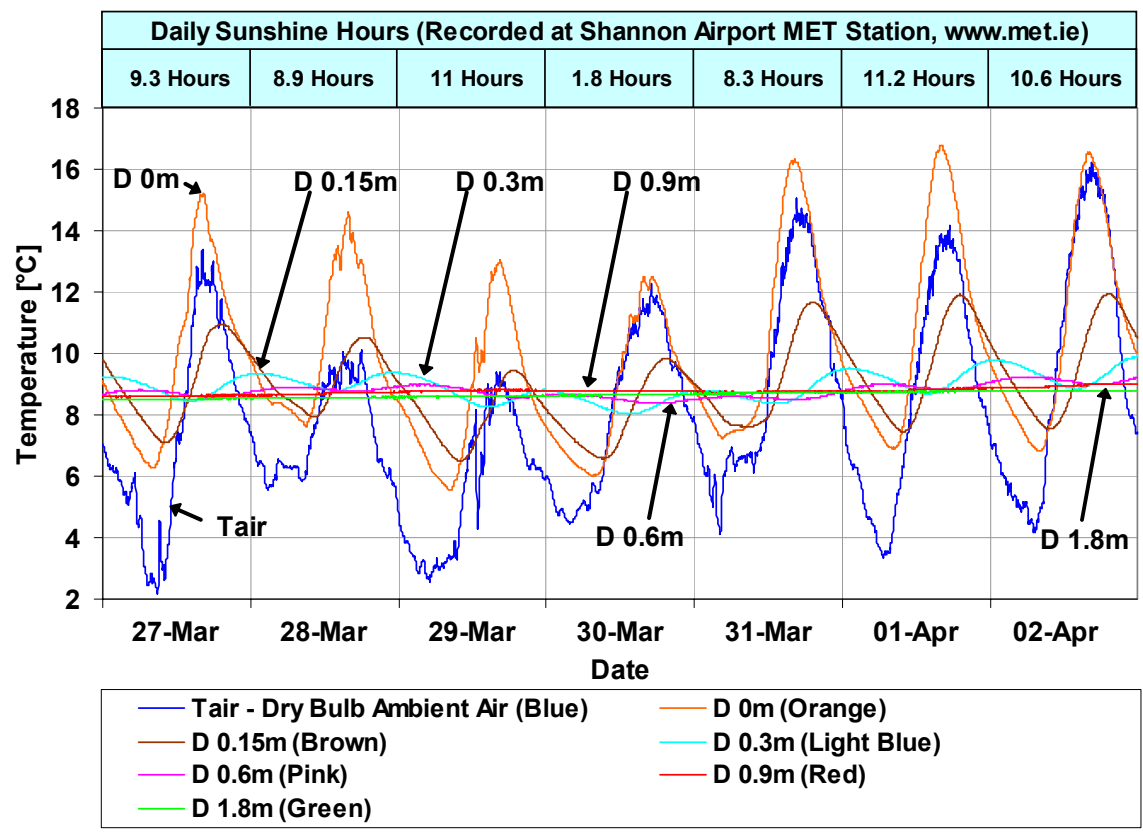

Figure 4: Fluctuations of air temperature and ground temperature with depth at the reference P1 location during the representative 'spring period'. 
It can be concluded from Figures 3 and 4 that the collector needs to be submerged at least $0.6 \mathrm{~m}$ to avoid diurnal ground temperature fluctuations, however, even greater temperature stability is provided at or below $0.9 \mathrm{~m}$, where the ground temperature increases by at least $1^{\circ} \mathrm{C}$ (Figure 3 ).

\subsection{Temperature gradients}

Figures 5 and 6 contrast temperature gradients from different profiles at the same instant. Measured temperature gradients within the collector region at P3, P4, P5 and $\mathrm{P} 7$ are compared with those from the control profile (P1). This comparison enables the impact of the heat pump operation to be assessed.

As the heat pump has been operating for over a month prior to the Winter period data in Figures 5(a) and (b), show there is a marked difference in ground temperatures inside (P3, P4, P5 and P7) and outside (P1) the collector region. There is no distinguishable temperature difference between P3, P4, P5 and P7.

The diurnal variation in near surface temperature is highlighted by comparing P1 in Figures 5(a) and (b). Figure 5(b) also displays the impact of the protracted (by Irish standards) period of cold weather, which has resulted in reduced ground temperatures to a depth of $1 \mathrm{~m}$ and when compared with Figure 5(a) this provides further evidence that better temperature stability is provided at or below $1 \mathrm{~m}$.

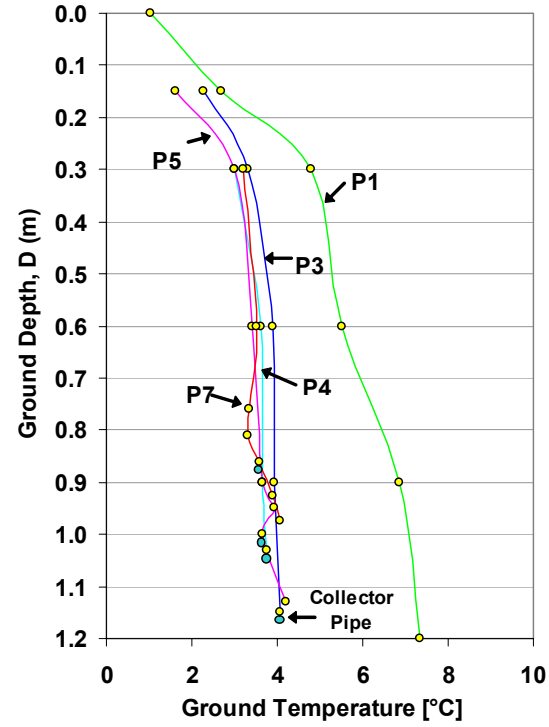

(a)

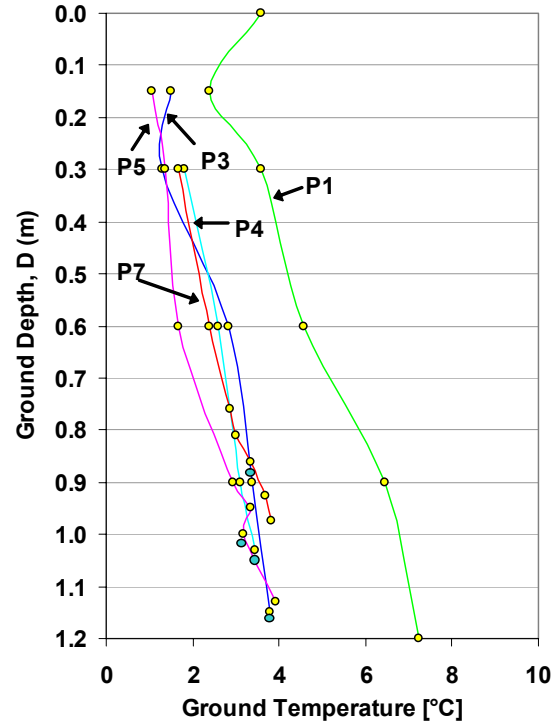

(b)

Figure 5: Variation in the temperature gradient with both depth and position during the Winter period (Table 1). (a) $05 \mathrm{Feb}$, midnight, (b) 08 Feb, midday. 


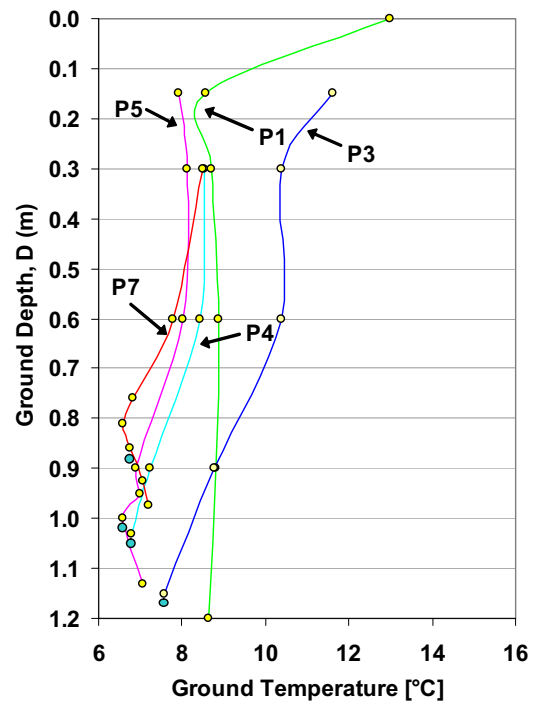

(a)

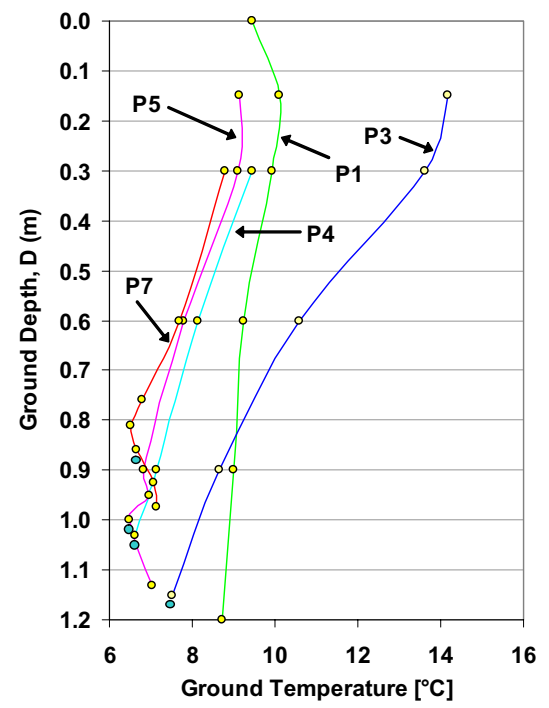

(b)

Figure 6: Variation in the temperature gradient with both depth and position during the Spring period (Table 1). (a) 01 Apr, midday, (b) 02 Apr, midnight.

Figures 6(a) and (b) present equivalent data for the warmer Spring period. While both figures present the variation in the temperature gradients with both depth and position during heat pump operation, measurement undertaken immediately prior to the activation of the heat pump on the March $31^{\text {st }}$ identified that the temperature gradients inside and outside the collector region were identical, indicating that the collector region had fully recovered the depleted thermal energy over its two week off period. Figures 6(a) and (b) therefore indicate the steady downward drift in ground temperature in the collector region, from those of $\mathrm{P} 1$, due to heat pump operation over a 36 hour period. Variation in the surface temperature of P1 again highlights diurnal effects.

The gradient recorded for P3 differs considerably from those of P4, P5 and P7 within the collector region. This was attributed to the fact that the ground composition in the region under the brick path at P3 (Figure 1 and 2) consisted mainly of gravel and not soil. The marked increase in the response of P3 is explained by the combined effects of the brick ground cover and the gravel foundation between the brick and collector sand bed at $0.9 \mathrm{~m}$. The brick and limestone based gravel has a thermal diffusivity approximately 2.2 times greater than that of soil $\left(\alpha_{\text {gravel }}=1.14 \times 10^{-6} \mathrm{~m}^{2} / \mathrm{s} ; \alpha_{\text {soil }}=5.07 \times 10^{-7} \mathrm{~m}^{2} / \mathrm{s}\right)$. This explains the large near surface fluctuations of P3 in Figures 6(b) and the steep temperature gradients to the collector at $1.15 \mathrm{~m}$ depth in Fig 6(b). 


\subsection{Further analysis at collector depth}

The time varying plot of soil temperatures at the collector depth is presented in Figures 7(a) and (b) for P3, P4, and P5 within the collector region. These are also contrasted against $\mathrm{P} 1$ outside the collector region.

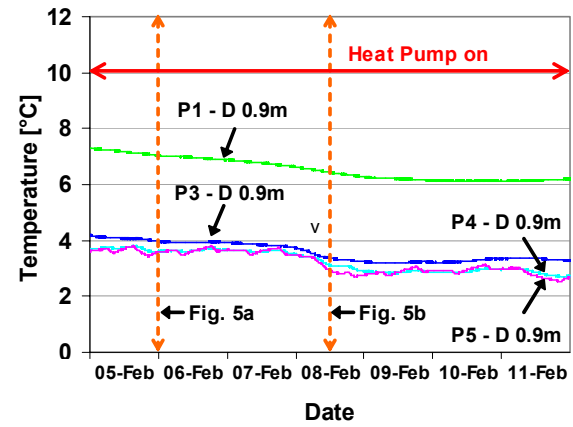

Figure 7: (a) Winter temperature at D $0.15 \mathrm{~m}$.

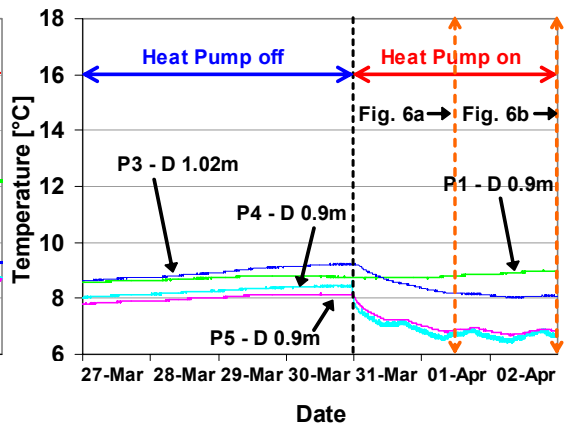

Date

Figure 7(a) presents data for the Winter period where the heat pump was continuously on generating consistently lower temperatures at P3, P4 and P5. There is close agreement between P3, P4 and P5 within the collector, with the small fluctuations in ground temperature generated by climatic effects.

Figure 7(b) presents data for the Spring period and highlights the impact of activating the heat pump on March $31^{\text {st }}$. The difference between P3 and the response of P4 and P5 is again highlighted. While diurnal effects are evident, steady-state conditions are reached after 3 days of operation producing approximately $3^{\circ} \mathrm{C}$ lower temperature than at $\mathrm{P} 1$.

\section{Conclusions}

a. A comprehensive test facility has been established to investigate the impact of diurnal, seasonal and climatic effects on the ground temperature gradients surrounding horizontal heat pump collectors in a maritime climate region.

b. The impact of ground composition (vegetation, cover and material type) as well as depth and heat pump operation on ground temperature gradients has also been established.

c. Inline with other studies measurements show that the greatest temperature fluctuation occurs at the surface and that the amplitude of the fluctuation decreases with depth and the time lag increases with depth.

d. While further analysis based on year round measurements is required, initial results indicate that (i) diurnal temperature fluctuations diminish to almost zero at $0.9 \mathrm{~m}$, while seasonal effects are still noticeable, (ii) temperatures in the collector region recover to normal within two weeks of no heat pump operation and (iii) the suitable collector depth for Maritime climates is approximately $1 \mathrm{~m}$. 
e. Reported experimental results are to be used as a basis for identifying and validating suitable models for predicting (i) ground temperature gradients (ii) optimum ground composition to maximise heat pump performance and (iii) thermal energy depletion and recovery rates.

\section{Acknowledgements}

The authors acknowledge the financial support of IRCSET, Enterprise Ireland and Dunstar Ltd. The assistance of Mark Deegan and also the GMIT Buildings and Estates Management is also acknowledged.

\section{References}

[1] Irish Government Department of the Environment, Heritage and Local Government, Irish National Climate Change Strategy 2007-2012, 2007.

[2] Intergovernmental Panel on Climate Change, Climate Change 2007: Impacts, Adaptation and Vulnerability, 2007.

[3] Popiel, C. O., Wojtkowiak, J., Biernacka, B., Measurements of temperature distribution in ground, Experimental Thermal and Fluid Science. 25: pp. 301-309, 2001.

[4] Mihalakakou, G., Lewis, J.O., Santamouris, M., Influence of different ground covers on the heating potential of earth-to-air heat exchangers, Renewable Energy. 7(1): pp. 33-46, 1996.

[5] Mihalakakou, G., Santamouris, M., Lewis, J.O., Asimakopoulus, D.N., On the application of the energy balance equation to predict ground temperature profiles, Solar Energy. 60(3-4): pp. 181-190, 1997.

[6] Inalli, M., Esen, H., Experimental thermal performance evaluation of a horizontal ground-source heat pump system, Applied Thermal Engineering. 24: pp. 2219-2232, 2004.

[7] Chacko P, T., Renuka, G., Temperature mapping, thermal diffusivity and subsoil heat flux at Kariavattom of Kerala, Proc. Indian Acad. Sci. (Earth Planet. Sci.). 111(1): pp. 79-85, 2002.

[8] Bi, Y., Chen, L., Wu, C., Ground Heat exchanger temperature distribution analysis and experimental verification, Applied Thermal Engineering. (22): pp. 183-189, 2002.

[9] Piechowski, M., Heat and mass transfer model of a Ground Heat Exchanger: theoretical development, International Journal of Energy Research. 23(7): pp. 571-588, 1999.

[10] Beltrami, H., On the relationship between ground temperature histories and meteorological records: a report on the Pomquet station, Global and Planetary Change. 29: pp. 327-348, 2001.

[11] Algren, A. B., Ground Temperature as Affected by Weather Conditions, Semi-Annual Meeting of the American Society of Heating and Ventilating Engineers. 1370: pp. 363-376, 1949.

[12] Timlin, D., Shillito, R., Pachepsky, Y., Kim, S.H., Fleisher, D., Quebedeaux, B., Two-Dimensional Soil Water and Temperature 
Dynamics under Row Crops: Modeling Approaches, Proceedings of 18th Congress of Soil Science, Philadelphia, Pennsylvania, USA. 2006.

[13] Pierson, F. B., Wight, J. R., Variability of near surface soil temperature on sage brush range land, Journal of Range Management. 44(5): pp. 491-497, 1991.

[14] Mei, V. C., Theoretical Heat Pump Ground Coil Analysis with Variable Ground Farfield Boundary Conditions, American Institute of Chemical Engineers Journal. 32(7): pp. 1986.

[15] Campbell, G. S., Norman, J. M., An Introduction to Environmental Biophysics, ed, ed. Vol., New York, Springer. 1998.

[16] Thomas, H. R., Welkin Li, C.L., Modelling transient heat and moisture transfer in unsaturated soil using a parallel computing approach, International Journal for Numerical and Analytical Methods in Geomechanics. 19(5): pp. 345-366, 1995.

[17] De Vries, D. A., Simultaneous Transfer of Heat and Moisture in Porous Media, Transactions American Geophysical Union. 39(5): pp. 909-915, 1958.

[18] Lohan, J., Burke, N., Greene, M., The Development of a Ground Source Heat Pump Characterisation Facility for the Irish Maritime Climate, Proceedings of Proceedings of Renewable Energy in Maritime Island Climates (REMIC2), Dublin Institute of Technology, Dublin, Ireland. pp.119-124, 2006.

[19] Stum, K., Sensor accuracy and calibration theory and practical application, Proceedings of National Conference on Building Commissioning, San Francisco, California, USA. 2006.

[20] Lohan, J., Burke, N., Greene, M., Climate Variables that Influence the Thermal Performance of Horizontal Collector Ground Source Heat Pumps, Proceedings of ESDA 2006: 8th Biennial ASME Conference on Engineering Systems Design and Analysis, Torino, Italy. 2006. 